\title{
Learning Object Educational Narrative Approach (LOENA): Using Narratives for Dynamic Sequencing of Learning Objects
}

\author{
Pollyana Notargiacomo Mustaro and Ismar Frango Silveira \\ Mackenzie Presbyterian University, São Paulo, Brazil
}

\section{polly@mackenzie.br ismar@mackenzie.br}

\begin{abstract}
Learning objects-based architectures often allows the creation of coarse-granular learning resources by aggregating learning objects retrieved mainly from well-structured public repositories. Nonetheless, the learning resource building process is not exactly trivial, since proper selecting and sequencing strategies must be applied in order to make it useful for learning purposes, as well as to make it fit in pedagogical goals previously established.

This paper shows LOENA (Learning Object Educational Narrative Approach), an architecture built over a theoretical basis that uses narrative-driven hypertext patterns to properly structure the sequencing of learning objects, providing a ready-to-use, pluggable way to implement learning paths in some teaching-learning context.
\end{abstract}

Keywords: learning objects, narratives, hypertext patterns, learning resources, collaborative learning

\section{Introduction}

The advance engendered by Internet established a divisor between predecessors mass technologies (television and video), which Lévy (1997b) used to call "molars", and the new ones - based in self-organization and appraisal of human qualities and processed involved -, named "molecular". According to this author, Informatics constitutes a molecular technique because it does not only distribute and reproduce information and messages in a more efficient way, but also allows the entire control of related microstructure of such distribution.

In a complementary way, the use of information networks connected by optical fibers and accessed through Internet are making deprecated paper-based text information-or at least compelling a new way to face it importance. Digital resources allow the construction and navigation through fluid text in a rhizomatic manner by hyperlinks and anchors. This scenario is exponentially amplified with different media supports as images, icons, animation, graphics, sound, and

Material published as part of this publication, either on-line or in print, is copyrighted by the Informing Science Institute. Permission to make digital or paper copy of part or all of these works for personal or classroom use is granted without fee provided that the copies are not made or distributed for profit or commercial advantage AND that copies 1) bear this notice in full and 2) give the full citation on the first page. It is permissible to abstract these works so long as credit is given. To copy in all other cases or to republish or to post on a server or to redistribute to lists requires specific permission and payment of a fee. Contact Publisher@InformingScience.org to request redistribution permission. even other hypertexts, which configures an unterritorial hypermedia approach over the cyberspace. Such dynamic environment could be compared with a live organism that was born, grows and needs to be feeding in order to continue to grow endlessness, with a lot of new, non-linear possibilities of unrolling. This metaphor is posed as a total opposition to the idea of a pre-projected, static "Information highway" or even the tra- 
ditional, memorization-based, linear learning approaches.

Nonetheless, such open, apparently chaotic architecture demands some sort of partial organization (Lévy, 2001), specially in teacher-learning situations, when knowledge organization is an essential piece of this intricate puzzle named Education.

It is a true challenge to make compatible the hypermedia characteristics and educational needs, especially in cases involving Learning Object Repositories (LORs), where there are in general thousands of elements developed for educational proposal - the LOs (Learning Objects), which must be arranged in a, connected, structured and mainly pleasant way. To put together both things, the present article suggests improving LO-based architectures with a narrative-driven approach, as well as collaborative elements.

\section{Conceptions of Hypertext and Narrative}

The concept of associations as communicational tools anchored in computing is presented first by Vannevar Bush (1945) when he proposes Memex. In this conceptual model contents could have non-linear access and non-hierarchical organization determined by associative indexation of documents, which is the truly ancestor of nowadays' hypertext and hypermedia-based systems. Nevertheless, the term Hypertext only appears in literature after Nelson's work (1965), when he shares his vision and glimpses what he called the dream file, a "file system that would have every feature a novelist or absent-minded professor could want, holding everything he wanted in just the complicated way he wanted it held, and handling notes and manuscripts in a subtle and complex ways as he wanted them handled" (p. 85). In sixty years he indicates three possible obstacles that he considers substantive enough not to be transposed: cost, need of machines, and design. However, the velocity of computational development made possible not only the transposition of these obstacles, as well as the implementation of hypertext and related technology:
"a body of written or pictorial material interconnected in such a complex way that it could not conveniently be presented or represented on paper. [...] Let me suggest that such an object a sys- tem properly designed and administrated, could have great potential for education, increasing the student's range of choices, his sense of freedom, his motivation, and his intellectual grasp. Such a system could grow indefinitely [...] [and] be build to accept growth, change and complex informa- tional arrangements" (Nelson, 1965, p. 96)

Lévy (2001) defines hypertext by two main points of view: technical and functional. It involves links that can be words, images, etc. or even another hypertexts, as well as it provides knowledge and data organization aiming to constitute a structure for communication and information acquisition. For this reason, hypertext architecture can be represented by mapping relations between links in a net.

Johnson-Eilola (1994) expands this definition by differing hypertext from hypermedia. While first one is characterized by textual elements, the second involves other types of media as image, sound, etc. and results in major interactivity by using multimedia elements. However, hypertextuality presents same characteristics in both cases. Lévy (1997a) identify six of these characteristics: metamorphosis (constantly mutation), heterogeneity of links and anchors, multiplicity of cuts and scales (which allows a hypertextual fractalization, where one single link can address an entire net), exteriority (net changes by extern fact), topology (paths based on proximity), and centers' mobility (exists several centers constantly move on the net).

These inherent elements, independent of media, unfolding and kaleidoscope (Lévy, 1997a) movements take place when inversion between user and hypertext/hypermedia occurs: user leaves "auditorium" and takes place on "stage", when he assumes the operating control to develop his own path and story. This approach is significantly different from linear, static structure usually found in educational process (especially in reading and writing), and offers innumerous 
possibilities to consider associative human thought and the personal process of building his own mental map of meanings through collaborative learning paths.

Wurman (1989) clarifies that a map shows that navigation usually is driven by informational direction, offering a reference point and allowing next step decisions. In LORs, it is possible to consider the concept placed by Lévy (1997a), for whom hypertexts could be oriented by mapping a domain as diagrams, networks or even easy-handled, dynamics concept maps (Novak, 1998), what helps in different manners to improve learning about specific field and related issues.

Besides that, the use of a hypertext structure to implement a hypermedia context with LOs involves a narrative educational strategy. When considering this aspect, it is relevant to define the concepts related to this area that can contribute with the present discussion. According to Bruner (1990, p. 43), narrative represents "a unique sequence of events, mental states, happenings involving human beings as characters or actors. [...] Their meaning is given by their place in the overall configuration of the sequence as a whole - its plot or fabula".

Narratives can present different plots. Tobias (1993) described twenty categories denominated as mater plots. For this article's proposal, there were select the following plots: search, adventure, rescue, and enigma.

In addition to that, organizing structure present in narratives can contextualize learning activities and facilitates the understanding of some topic (Wells, 1986). It occurs because "without a narrative, life has no meaning. Without meaning, learning has no purpose. Without a purpose, schools are detention houses, not attention" (Postman, 1995, p. 7). Postman's assertion is valid both for presential and/or online educational proposals, and implies in reflection of narrative-driven activities in learning.

\section{Narratives and Collaborative Learning}

People are surrounded by and establish contact with narratives since infancy, more specifically when they start to be told tales by parents, tutors, teachers, and so on. Furthermore, according to Carter (1993), the capture of complexity and interrelation among natural phenomena and human being occurs mainly through stories. This author also argues that the complete understanding of thought requires story identification, which leads to the organization of a particular chaining of events.

For educational purposes, a possible perspective is to construct an interaction model through a script that focus learning outcomes and use of distinct elements that support knowledge building. As Murray (1997) points out, digital environments are characterized by some constitutive elements, as the procedural disposition to execute serial rules, participation related to interaction, spatial thought by being in scenes where it is possible to navigate and create personal paths, and encyclopedic data organizing. However, she emphasizes that these properties changes the way scripts are elaborated, since they are no more centered in possibilities of action to be driven to unspecific event plots that cover the rules of action in order to establish a complex, intricate plot opened to collaborative interaction and dynamic action.

In this context, narrative-centered learning approach can be used to constitute a resource for LOoriented architectures, since narratives could help to achieve adequate LO sequencing for certain pedagogical goals. Narrative-based environments are commonly characterized by their engaging, curiosity, challenging and motivating activities (Malone, 1981), whose linkage with hypermedia elements helps to promote problem-based activities grounded in story-centric approach.

Barrows (2000) defines Problem-Based Learning (PBL) as a procedural learning approach that considers some problems of curriculum and the need of developing skills related to problem solving, critical knowledge, and team-work, for example. Such abilities, if developed by a student, 
would help him to face real challenges, and he would be able to elaborate proper steps of resolution for such real life problem. The design of situation involving PBL can be related to Bruner early (1960) proposal, in which it is described a spiral-shaped curriculum that is organized by major issues and concepts considered relevant to society.

In a complementary way, Bruner's spiral curriculum can be comparable to course structure philosophy of learning object: bottom-up approach (Mustaro et al., 2006) and Gagné-oriented spiral approach (Silveira et al., 2005). According to these works, concepts already learned in different levels become foundations of new educational challenges in a gradual, connected way.

This approach covers diverse elements involves in learning as competence acquisition from associative perspective, discover principles and knowledge building in individual and/or social activities, what results in development of collaborative learning (Figure 1).

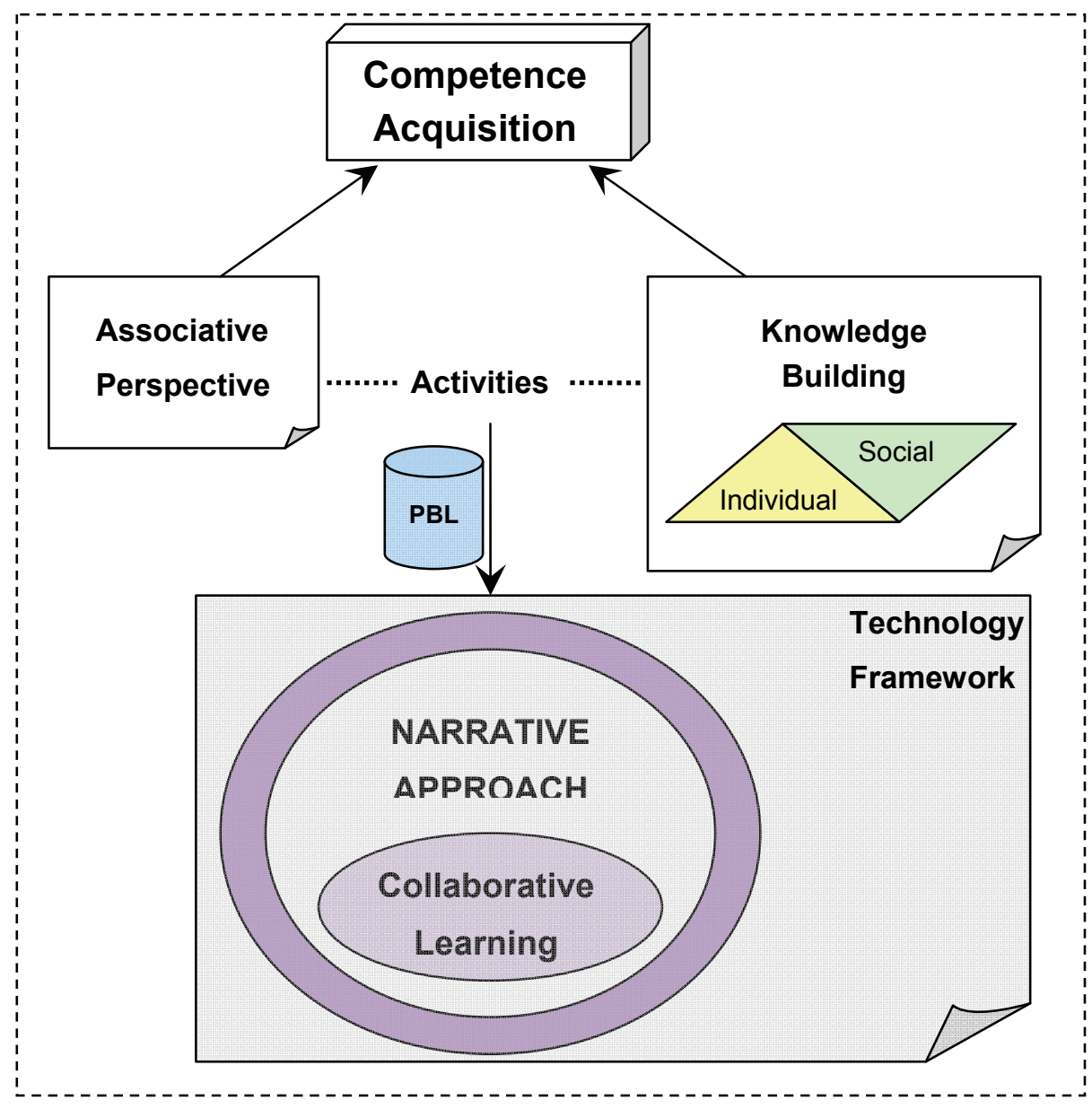

Figure 1 - Narrative approach of Collaborative Learning

The technological context related to net society amplifies and potentates the development and use of collaborative digital environments for educational intentions. This scenario emphasizes interaction and an expressive need of changing of current teaching-learning process paradigm. In this direction, implementation of Computer-Supported Collaborative Learning (CSCL) features with narrative support requires change of focus from teacher-centered, classical expositive experiences to dynamic, adaptive web-based context. 


\section{A Pattern-Oriented Visual Language for Describing Narratives}

Patterns are proven solutions for recurring problems, generally distilled from the experiences of experts. A very large range of patterns exist in diverse areas of Computer Science, though GoF Design Patterns (Gamma et al., 1995) are widely the most well-known set of patterns among all others.

Bernstein (1998) proposes an unclosed set of visual elements as a pattern language for Hypertext. According to him, these patterns are taking from literary fiction because "rather, a variety of economic and cultural factors sometimes encourage experimentation in narrative rather than technical writing or journalism". These patterns try to establish a set of well-known kinds of interaction a hypertext-based experience can have, and mainly, which sort of narrative process is presented to user and which kind of narrative the users choose to follow.

The superset of patterns proposed by Bernstein (1998) is composed by:

- Cycle

- Counterpoint

- Mirrorworld

- Tangle

- Sieve

- Montage

- Neighborhood

- Split/Join

- Missing Link

- Navigational Feint

Table 1 exposes such set, with some expansions and adaptations for Hypermedia Narrative. Icons in blue represent proposals of patterns representation that do have no symbol associate to them in Bernstein (1998) work:

Table 1: Cycle-related patterns

\begin{tabular}{|c|l|}
\hline Dycle & $\begin{array}{l}\text { A Cycle establishes a mechanism where reader returns to a previously-visited } \\
\text { node and has a possibility to go to different path. }\end{array}$ \\
\hline Doyce's Cycle & $\begin{array}{l}\text { Joyce's Cycle institute a structure where reader split a previously-visited } \\
\text { component of the hypertext and keeps on a previously-traversed path through } \\
\text { one or more space since cycle is collapsed. }\end{array}$ \\
\hline Wouglas' Cycle & $\begin{array}{l}\text { A Web Ring is formed by hypertexts that constitute a tour of a subject to } \\
\text { share readers. }\end{array}$ \\
\hline Contour & $\begin{array}{l}\text { Contour allowing cycles that trespass each other in a free movement that go } \\
\text { through cycles' paths defined by each one. }\end{array}$ \\
\hline
\end{tabular}


In Cycle-related set of patterns (Kolb, 1994; Bernstein, 1998), hypertext paths emerge naturally from argumentation practice. Cyclical repetition is a commonplace in hypertext; webwriters, webdesigners and instructional designers can plan some "breadcrumbs" to guide user in new trajectories in order to break cycles. This recursive structure enlarges key points while puts in background others, establishing access equality in a multidimensional way.

For instance, in educational environment it is possible to use a Contour, a case configured by cycles that direct between itself allowing free and easy movement among cycles and paths in each cycle by restrictions. Another pattern that can contribute significantly is Montage, because it offers a possibility of using multiple start points.

Figure 2 shows an example of Contour hypertext pattern. The learning context of this example refers to a Software Engineering class, studying GoF Design Patterns (Gamma et al., 1995). As the author specifies, there are three main families of these patterns (Creational, Structural and Behavioral).

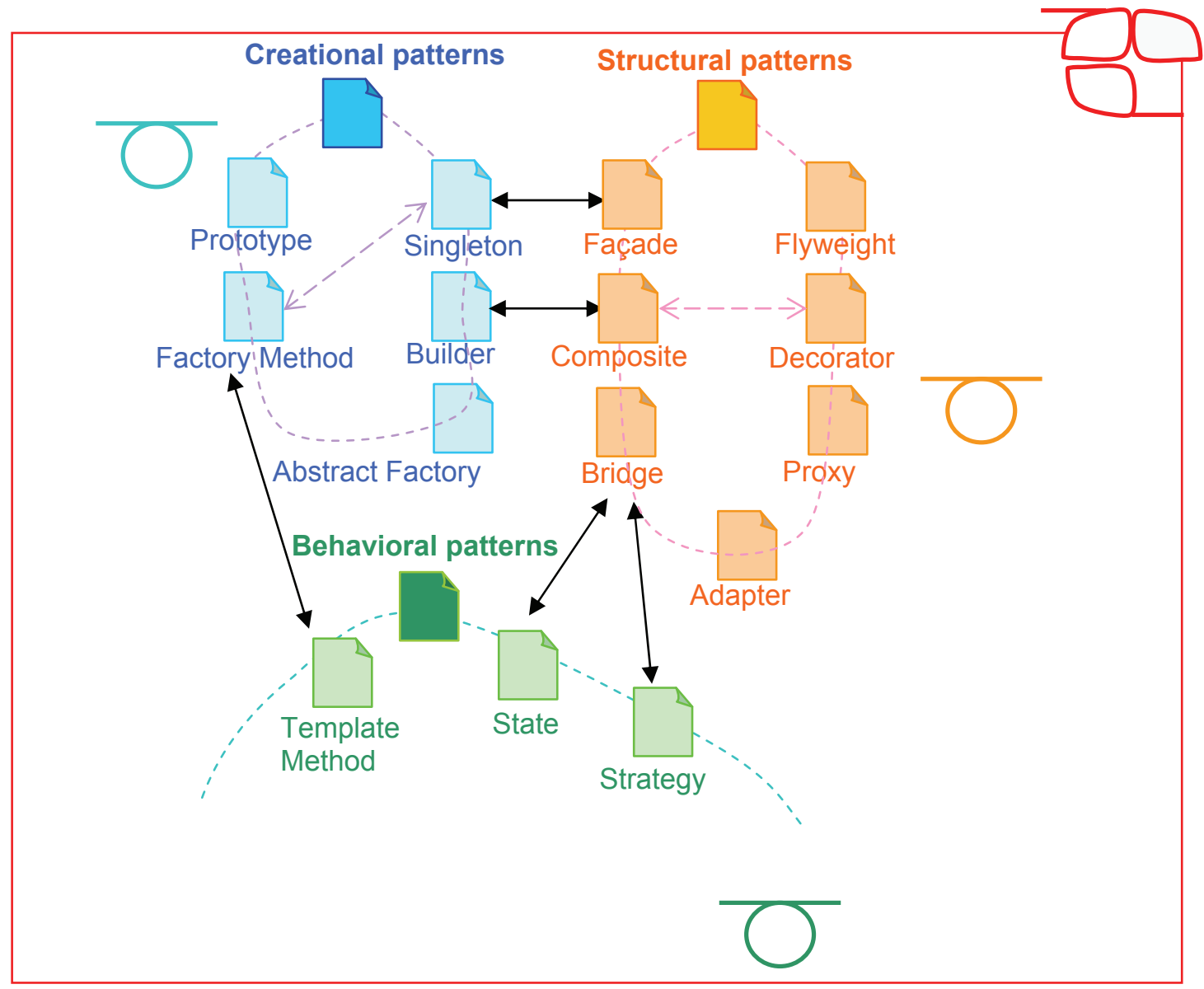

Figure 2 - Contour and Cycle hypertext patterns

At a first sight, each family constitutes a Cycle (as is, Joyce's or Douglas', depending on the implementation), with some well-defined breadcrumbs. For instance, there are breadcrumbs in Singleton e Builder. However, these strategy leads user to another cycle (Structural) and so on.

Table 2 shows a subjacent set of other hypertext patterns (with same blue codification to represent icons proposal to patterns), again expanded from Bernstein (1998): 
Table 2: Hypertext Patterns Architecture

\begin{tabular}{|c|c|}
\hline Counterpoint & $\begin{array}{l}\text { Counterpoint interleaves or combine together themes/responses of two } \\
\text { voices in an alternate way. }\end{array}$ \\
\hline Mirrorworld & $\begin{array}{l}\text { Mirrorworlds establish an intertextuality narrative of different voice or op- } \\
\text { posite perspective that hold coherence. }\end{array}$ \\
\hline Tangle & $\begin{array}{l}\text { In Tangle reader have a lot of link possibilities to choice without guidance } \\
\text { information. }\end{array}$ \\
\hline Sieve & $\begin{array}{l}\text { Sieves are characterized by sort of one or more layers of choice to institution } \\
\text { of sections or even episodes. }\end{array}$ \\
\hline & $\begin{array}{l}\text { Montage permits emerge of simultaneous distinct writing spaces since rein- } \\
\text { force each other while carrying individual identities. }\end{array}$ \\
\hline Neighbc & $\begin{array}{l}\text { Through Neighborhood association among nodes, shared ornament, or com- } \\
\text { mon navigational landmarks is possible to establish proximity. }\end{array}$ \\
\hline Split/Join & Split/Join interlaces and put together two or more sequences. \\
\hline Missing Link & $\begin{array}{l}\text { Missing Link is defined as a link that does not exist, but is suggested in hy- } \\
\text { pertext. }\end{array}$ \\
\hline & $\begin{array}{l}\text { Feint point out presence of a navigational opportunity and notify reader fu- } \\
\text { ture possible choices that may be pursued. }\end{array}$ \\
\hline
\end{tabular}

The elements of Table 2 complement cycle-related patterns by presenting interactive possible ways to combine or put together elements that implements dynamic and complex narrative uni- 
verses. Meanwhile, the elements of Table 1 and 2 require a supporting framework, which is detailed in next session.

\section{LOENA Framework}

One possibility to implement this architecture is to use abstraction based on diegesis. Diegesis can be considered as group of events narrated through fictional space-temporal dimension of narrative (Aumont et al., 1992). According to Genette (1972), the storyteller position facing diegesis is characterized in tree ways: homodiegetic, heterodiegetic, and autodiegetic. The first one is related to story where active character is responsible to narrative. The second type is determined by an external narrator. Finally, the third one involves the story being told by protagonist itself.

This multiple scenario can comport also level proposals: intradiegetic (concerns only to the universe of a story), metadiegetic (determined by introduction of a character by narrator to tell a secondary story), and extradiegetic (when some story character tells other story and turn his status in storyteller of new one).

From this point of view, diegesis can contain plots. Because of that, the presented model combines diegesis elements (context, characters, conclusion, etc.) with a plot-driven approach (which requires a resolution for a challenge, for example) to establish some educational strategy. It implies in a nonlinear proposal determined in part by learning styles and collaborative learning (Figure 3).

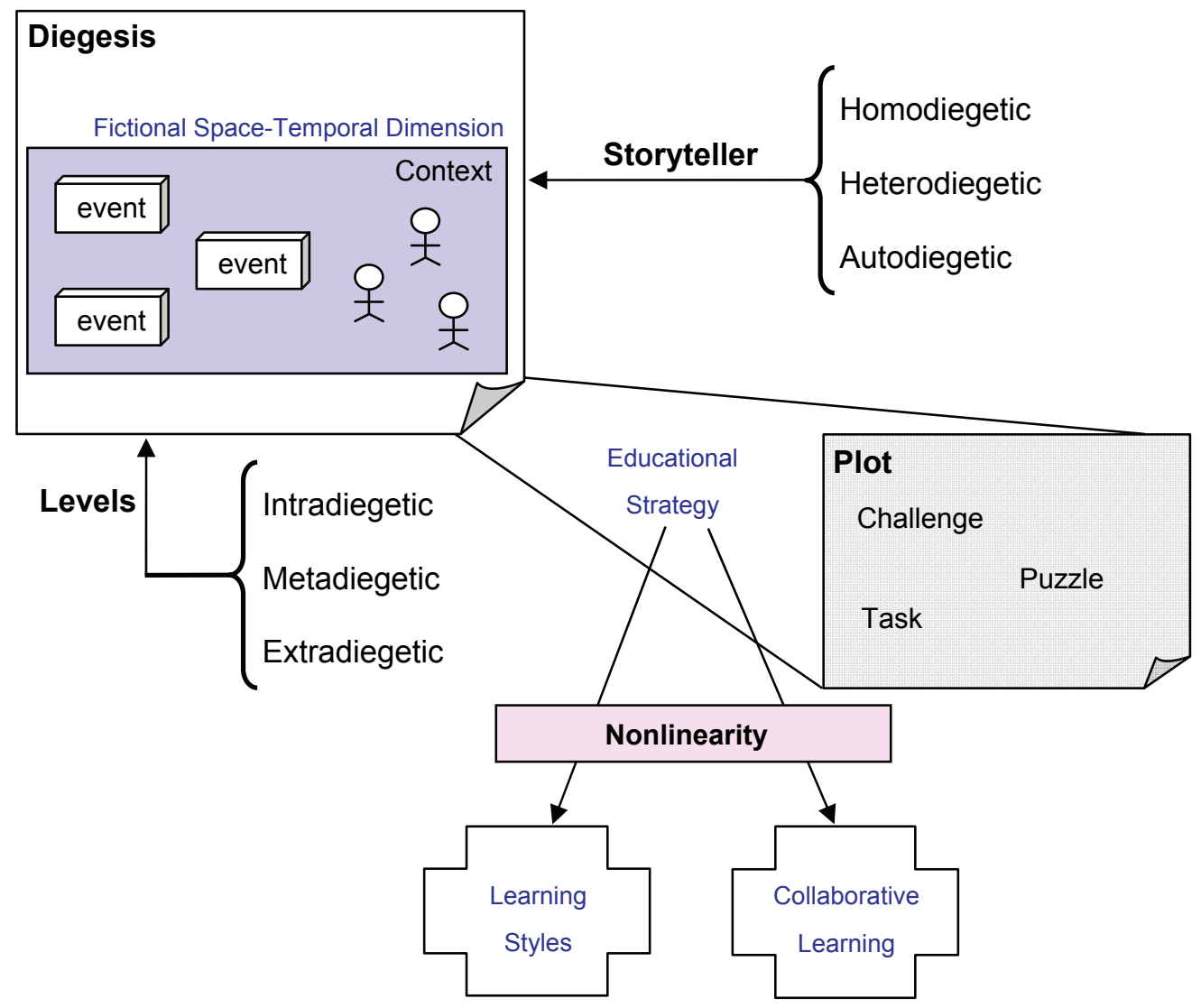

Figure 3 - LOENA nonlinear diegesis and educational model

To implement this, the following diagram in Figure 4 shows the core of LOENA framework. In the top side, there are the hypertext narrative patterns described before, which can be used in the 
authoring process of learning resources. In the diagram's bottom side, there are some pre-built narratives (Tobias, 1993).

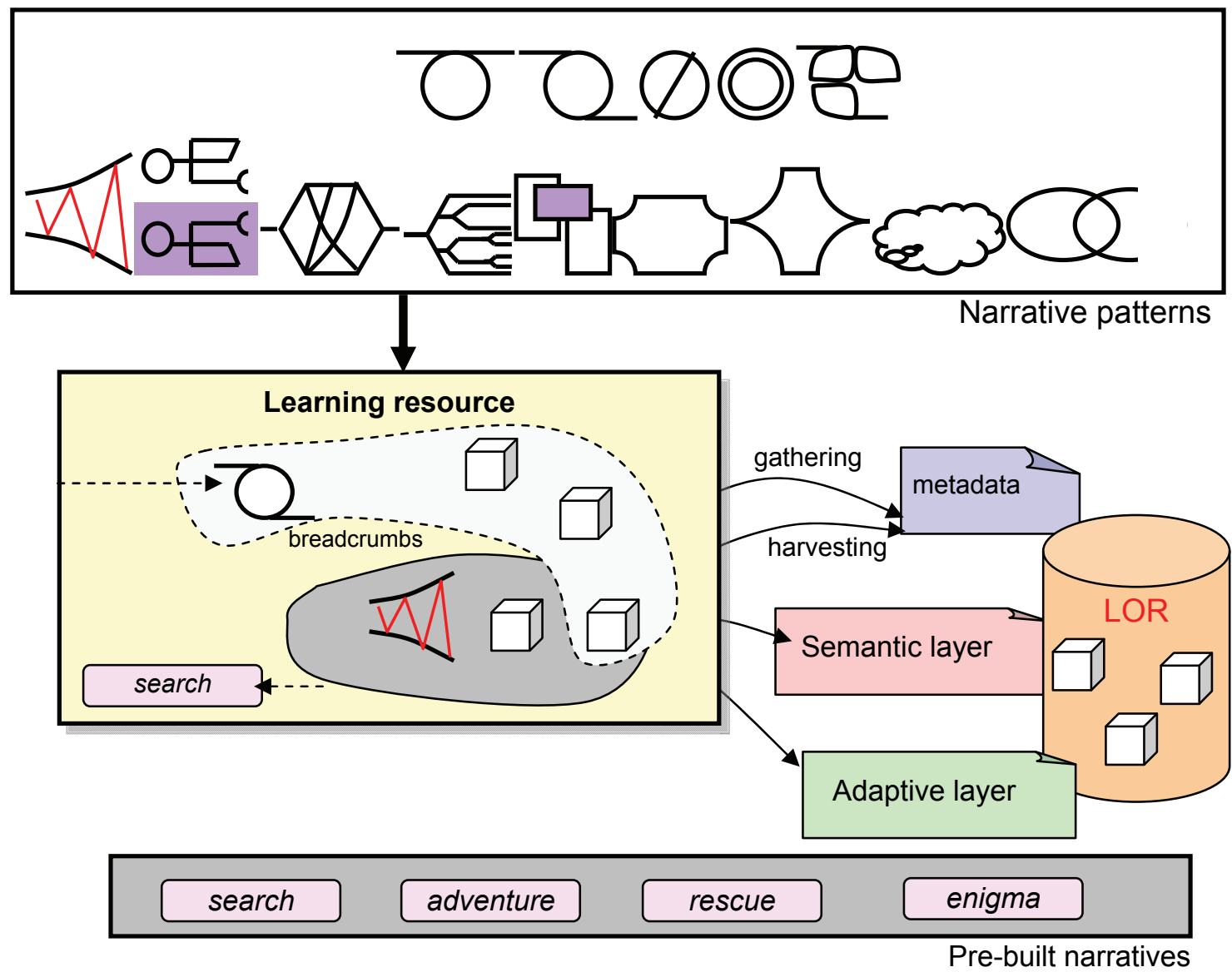

Figure 4 - LOENA core architecture

In the case depicted in Figure 4, a Learning Resource is being constructed by collecting LOs from a LOR (or a federation of LORs). Coarse-granular learning resources are mainly built by aggregating LOs, which usually come from LORs in a diverse variety of ways. It goes beyond the goals of this paper to explain deeply the ways LOs might be retrieved from LORs. Silveira et al. (2007) present a discussion about the subject.

The contribution of LOENA architecture is to provide a pluggable way to insert narrative patterns as sequencing elements between LOs. In Figure 4, two coarse learning resources are being formed by referencing some fine-granular LOs, organized through narrative patterns (in the case a Joyce's Cycle and a Counterpoint. More than this, a pre-built whole narrative ("search") is being plugged to the resource.

By providing a set of narrative patterns and the possibility of building new pluggable narratives from combining such patterns, LOENA brings reuse to a level that is different from the one that generally obtained from LO reuse. Whilst reuse of LOs is mainly related to context-awareness, data granularity and functionality cohesion, narrative reuse leads to a higher-level flavor of reuse, where not only objects are meant to be published, shared and reused, but also their organization, presentation schema and relationships they maintain with other objects and even students. 


\section{Conclusions and Further Work}

The presented proposal allows the merging of contemporary technology support for teachinglearning activities (as Learning Objects Theory and LORs) with abstract elements like Hypertext Patterns approach to support the creation of more fluid and dynamic learning resources. On the other hand, from teacher's point of view, it is possible to script diegesis with plots to individual context, since it also keep granularity of individual learning object.

Further works will involve the development of appropriate and intuitive object-driven interface that convert abstract script conception in SCORM-compliant XML data, which can be used by engine responsible for management of individual and collaborative learning interactions. Collaborative definition of dynamic narratives is also meant to be supported by this architecture.

\section{References}

Aumont, J., Bergala, A., Marie, M., Vernet, M., \& Neupert, R. (1992). An esthetics of film. Austin: University of Texas Press.

Barrows, H. S. (2000). Problem-based learning applied to medical education. Southern Illinois: University Press.

Bernstein, M. (1998). Patterns of hypertext. Proceedings of HyperText 98, Pittsburgh: ACM, 21-29.

Bruner, J. (1990). Acts of meaning. Cambridge, Massachusetts: Harvard University Press.

Bruner, J. (1960). The process of education. Cambridge, Massachusetts: University Press.

Bush, V. (1945). As we may think. Atlantic Monthly, 176(1), 101-108.

Carter, K. (1993). The place of story in the study of teaching and teacher education. Educational Researcher, 22(1), 5-12.

Gamma, E., Helm, R., Johnson, R. \& Vlissides, J. (1995). Design patterns: Elements of reusable objectoriented software. Addison-Wesley.

Genette, G. (1972). Figures III. Paris: Seuil.

Kolb, D. (1994) Socrates in the labyrinth: Hypertext, argument, philosophy. Watertown, Massachusetts: Eastgate Systems.

Johnson-Eilola, J. (1994). Reading and writing in hypertext: Vertigo and euphoria. In C. L. Selfe \& S. Hilligoss (Eds.), Literacy and computers: The complications of teaching and learning with technology (pp. 195-219). New York: MLA.

Lévy, P. (1997a). As tecnologias da inteligência: o futuro do pensamento na era da informática. [Intelligence technologies: the thought future in informatics era]. Rio de Janeiro: Editora 34.

Lévy, P. (1997b). Collective intelligence: Mankind's emerging world in cyberspace. New York: Plenum Press.

Lévy, P. (2001). Cyberculture. Minneapolis: University of Minnesota Press.

Malone, T. W. (1981). What makes computer games fun? Byte, 6, 258-277.

Mustaro, P. N., Silveira, I. F., Omar, N. \& Stump, S. M. D. (2007). Structure of storyboard for interactive learning objects development. In A. Koohang \& K. Harman (Eds.), Learning objects and instructional design (pp. 253-280). Santa Rosa, California: Informing Science Press.

Murray, J. (1997). Hamlet on the holodeck. The future of narrative in cyberspace. New York: The Free Press.

Novak, J. D. (1998) Learning, creating, and using knowledge: Concept maps as facilitative tools. In Schools and corporations. New York: Lawrence Erlbaum Associated Ed. 
Nelson, T. H. (1965). A file structure for the complex, the changing and the indeterminate. $A C M 20^{\text {th }} \mathrm{Na}$ tional Conference. 84-100.

Postman, N. (1995). The end of education: Redefining the value of school. New York: Knopf.

Silveira, I. F., Omar, N. \& Mustaro, P. (2005). Reusability and interoperability of adaptive learning objects repositories. In XVI SBIE - Brazilian Symposium on Informatics and Education. Juiz de Fora, Brazil.

Silveira, I. F., Omar, N. \& Mustaro, P. (2007). Architecture of learning objects repositories. In K. Harman \& A. Koohang (Eds.), Learning objects: Standards, metadata, repositories, and LCMS (pp. 131-156). Santa Rosa, CA: Informing Science Institute.

Vanoye, F. (1994). Ensaio sobre a análise fílmica. [Essay about filmic analysis]. São Paulo: Papirus. (Coleção Ofício de Arte e Forma)

Wells, C. G. (1986). The meaning makers: Children learning language and using language to learn. Portsmouth, NH: Heinemann.

Wurman, R. S. (1989). Information anxiety. New York: Doubleday.

\section{Biographies}

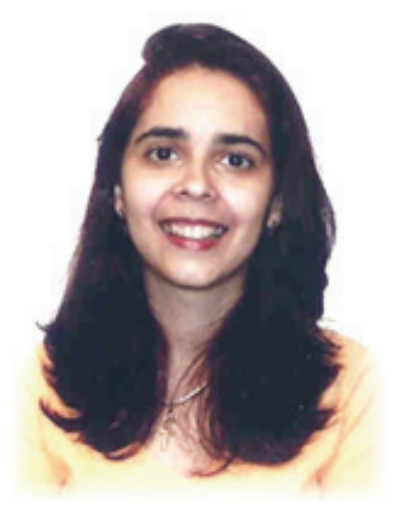

Pollyana Notargiacomo Mustaro obtained her PhD in Education (São Paulo University, 2003), being specialized on Internet hackers' Knowledge Building Process. Nowadays, she is a professor at Mackenzie Presbyterian University. Her research areas include Learning Objects Theory, Learning Styles, Instructional Design, Distance Learning and Hypertext Theory.

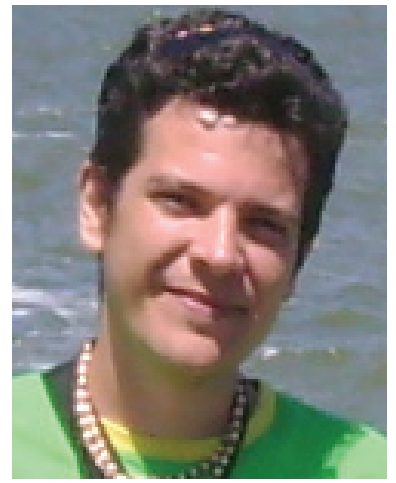

Ismar Frango Silveira defended his $\mathrm{PhD}$ thesis in Distributed Objects applied to Virtual Reality-based Learning Environments in May 2003, at São Paulo University. Currently, he is involved with researches in Adaptive Learning Objects, Design Patterns and Collaborative Learning, among other areas. He presently teaches at Mackenzie Presbyterian University and Cruzeiro do Sul University, both in São Paulo, Brazil. 